\title{
WRIGHT MILLS E A SOCIOLOGIA DO CONHECIMENTO: PRAGMATISMO E INTERACIONISMO SIMBÓLICO'
}

\section{WRIGHT MILLS AND THE SOCIOLOGY OF KNOWLEDGE: PRAGMATISM AND SYMBOLIC INTERACTIONISM}

Diogo Valença de Azevedo Costa*

\section{Introdução}

Os primeiros trabalhos sociológicos de Wright Mills (1916-1962) apresentam fortes afinidades com a filosofia pragmatista norte-americana e com o interacionismo simbólico da Escola de Chicago. Tais afınidades foram marcantes e intensas no início de sua trajetória acadêmica, porém continuam a se fazer presentes em publicações posteriores do autor, a exemplo da trilogia clássica sobre a estrutura de poder nos Estados Unidos, The New Men of Power: America's labor leaders (1948), White Collar: the american middle classes (1951) e The Power Elite (1956). 0 pensamento político de Mills se vincula aos horizontes democráticos e participativos do liberalismo clássico, corrente ideológica a partir da qual ele irá se integrar a algumas das tradições filosóficas e teóricas das ciências sociais então em processo de consolidação nos Estados Unidos.

0 liberalismo clássico seria o pano de fundo de análise crítica da tradição filosófica pragmatista e da influência desta sobre a vertente sociológica da qual ele mesmo se considerava herdeiro. A presença da psicologia social meadeana, ponto de partida de muitos trabalhos da Escola de Chicago, iria se juntar a um enfoque weberiano mais amplo dos conflitos societários em torno da monopolização do tipo de poder especificamente político disseminado nas sociedades modernas, objeto de disputa em diversas

\footnotetext{
* Doutor em Sociologia pela Universidade Federal de Pernambuco (UFPE). Professor Associado da Universidade Federal do Recôncavo da Bahia - UFRB (Cachoeira/BA/BR). E-mail: valencadiogo@hotmail.com; valencadiogo@ufrb.edu.br

1. Uma primeira versão deste artigo foi apresentada no Grupo de Trabalho "Teoria Social: agendas, desafios e perspectivas” durante o $41^{\circ}$ Encontro Anual da ANPOCS em Caxambu-MG (2017).
} 
instâncias institucionais de um mundo burocratizado e com diferentes probabilidades de controle sobre o destino dos indivíduos e da coletividade.

Os modos como os agentes sociais definem suas próprias circunstâncias históricas, sociais e políticas, atuando de acordo com tais defınições da realidade em meio às oportunidades por eles mesmos vislumbradas de ocupar as posições mais privilegiadas nas estruturas de dominação da sociedade, integram um dos métodos interpretativos da sociologia política de Wright Mills. Essa herança conjunta do pragmatismo e do interacionismo simbólico irá fazer com que o enfoque das estruturas de poder esteja sempre acompanhado de considerações aprofundadas sobre o papel dos indivíduos, de grupos e categorias sociais nos rumos das mudanças sociais e políticas.

0 propósito deste artigo será apontar as afinidades e influências diretas da filosofia pragmatista norte-americana e do interacionismo simbólico na sociologia do conhecimento de Wright Mills. Para tanto, serão analisadas as duas primeiras partes de sua tese de doutorado de 1942, originalmente intitulada $A$ sociological account of pragmatism: an essay on the sociology of knowledge. Somente após pouco mais de duas décadas esse trabalho sairá em formato de livro, desta vez com um título mais explícito quanto ao seu conteúdo sociológico de análise das mudanças educacionais na esfera do ensino superior nos Estados Unidos, Sociology and pragmatism: the Higher Learning in America (1966). 0 próprio Mills havia se desinteressado da publicação de sua tese de doutorado, pois seus interesses de investigação já haviam se voltado para o estudo das lideranças sindicais nos Estados Unidos. No entanto, o pragmatismo e o interacionismo simbólico já haviam deixado uma marca profunda nos horizontes políticos e teóricos de sua prática sociológica. A análise propriamente dita das duas primeiras partes do livro de Mills sobre pragmatismo e sociologia será precedida de algumas considerações relativas à sua fortuna crítica, a fim de situar os contextos históricos de sua produção teórica e os desafios que os intérpretes de seu pensamento lançam, ao apontarem algumas de suas limitações conceituais e metodológicas, às principais formulações contidas no conjunto de suas contribuições para as ciências sociais.

\section{A sociologia pragmatista de Wright Mills e sua fortuna crítica}

Ainda está por ser realizado, pelo menos no Brasil, um balanço o mais abrangente e exaustivo possível do estado da arte em torno da produção intelectual de Wright Mills, na sua dupla dimensão sociológica e política. Esse balanço deve assumir um caráter histórico, dado que as avaliações críticas sobre o pensamento do autor se transformaram profundamente a partir de mudanças das circunstâncias políticas nacionais e internacionais dos Estados Unidos, de um lado, e de acordo com as reviravoltas teóricas e metodológicas das ciências sociais aqui tomadas num plano mundial de disputas hegemônicas de poder entre nações, de outro. A própria assimilação de Mills em outros países, como alguns casos latino-americanos deixam transparecer, em particular Brasil e Argentina, parece ter sido informada pelo tom polêmico de seus protestos contra a hegemonia parsoniana na sociologia norte-americana. Mills não seria visto propriamente como um teórico, mas como alguém que se dispôs a criticar, num estilo tomado muitas vezes como panfletário, as 
tendências internacionalmente hegemônicas da sociologia norte-americana, as quais caracteriza ironicamente como a grande teoria de Talcott Parsons e o empirismo abstrato de Paul Lazarsfeld. Em que pese alguns elementos de verdade, essa imagem se revela bastante caricatural, pois não considera suas valiosas contribuições para a teoria da estratificação social ou, ainda, as sugestões de seus escritos para a construção de sínteses teóricas nas ciências sociais.

Numa classificação preliminar bastante aproximativa, construída pela combinação de critérios temáticos e cronológicos, a produção de uma fortuna crítica sobre a sociologia de Mills pode ser dividida, historicamente, em três grandes momentos ${ }^{2}$ : o primeiro deles (décadas de 1950 e 60) se destaca por uma falsa lógica polarizada de veneração ou detratação (SUMMERS, 2008b, p. 108) e tem início com Mills ainda em vida - momento esse mais caracterizado por ataques pessoais e argumentos apaixonados a favor ou contrários às suas posições políticas radical-liberais, considerando que se estava em pleno macarthismo nos Estados Unidos. Os nomes mais importantes dessa fase são Irving Louis Horowitz (1963; 1964; 1966; 1983) e Tom Hayden (2016[1964]). No caso do primeiro nunca será demais reconhecer seu papel pioneiro na divulgação de escritos de Mills que de outro modo poderiam ter permanecido quase inéditos ou totalmente desconhe- cidos. Na ânsia de responder às críticas conservadoras mais duras contra o autor, Horowitz tendia a certos exageros como o de considerar Mills "o maior de todos os sociólogos estadunidenses”, igualando-o a figuras históricas como Sócrates, Martin Luther King e Marx (OAKES, 2016). Além disso, as críticas mais recentes aos textos de Horowitz sobre Mills apontam um tom acentuadamente laudatório e de defesa - o que nem sempre é verdadeiro, pois ambos discordavam com intensidade na avaliação política da Revolução Cubana (MONTECINOS, 2016). No entanto, Horowitz (1983) escreveu um dos primeiros estudos mais completos sobre o autor no sentido de abranger diferentes aspectos e fases dos escritos acadêmicos e políticos de Mills, baseando-se em arquivos pessoais e entrevistando pessoas que haviam convivido com o sociólogo norte-americano. Trabalhos posteriores sobre o autor tiveram que dialogar com esse esforço precursor, corrigindo, contudo, algumas de suas imperfeições factuais e certos exageros interpretativos.

Na década de 1960, Tom Hayden era um jovem estudante da Universidade de Michigan então iniciando sua militância no movimento estudantil. Pouco antes da morte de Mills em 1962, Hayden havia acabado de escrever o manifesto coletivo da Students for a Democratic Society (SDS), como ficou mundialmente conhecida a Declaração de Port Huron $^{3}$. Wright Mills figurava como a prin-

2. 0 autor do presente artigo desenvolve atualmente uma pesquisa mais ampla intitulada "Wright Mills em questão: um estudo sobre a sua fortuna crítica no Brasil e Estados Unidos”. 0 esquema a seguir apresentado deve ser lido como um resultado ainda provisório, fazendo-se oportuno mencionar que tais investigações estão conduzindo a uma comparação entre as recepções de Mills no Brasil e na Argentina.

3. Sobre os movimentos estudantis dos anos 1960 nos Estados Unidos, ver Rodrigo Freitas de Sousa, A Nova Esquerda Americana: de Port Huron aos Weathermen (1960-1969), Rio de Janeiro: Editora FGV, 2009. As influências dos escritos de Mills sobre tais movimentos estudantis são aí politicamente debatidas (SOUSA, 2009, p. 61-69). 
cipal influência política e intelectual desse manifesto. Logo depois, no ano de 1963, Hayden começa a redigir na escola pós-graduada de Ann Arbor a primeira tese acadêmica sobre Mills, identificando-o como um "nômade radical". A tese foi finalizada em 1964 e, depois disso, Hayden decide colocar à prova suas ideias políticas, inspiradas no estudo da obra de Wright Mills, a partir de sua vivência no movimento estudantil. Originária do movimento estudantil, cujos princípios ideológicos já estariam presentes no Port Huron Statement, a Nova Esquerda Americana se pautava pela crítica à alienação dos indivíduos na sociedade de massas, a multidão solitária de classes médias norte -americanas em geral apáticas e indiferentes às grandes tragédias históricas e decisões políticas mais fundamentais de sua época, justamente as preocupações centrais das investigações sociológicas de Mills. Em outras palavras, os escritos de Hayden sobre o autor assumem uma feição engajada, mais voltada para a incorporação de suas análises da estrutura de poder nos Estados Unidos. Trabalhos mais sistemáticos sobre a sociologia de Wright Mills dependeriam de circunstâncias intelectuais outras, mais distanciadas e independentes em termos de avaliação crítica.

0 segundo momento dessa produção de uma fortuna crítica sobre Mills se caracteriza por um teor mais exigente de crítica e rigor acadêmico na reconstrução do conjunto de seu pensamento sociológico e político. Em 1984, Rick Tilman publica C. Wright Mills: a native radical and his American intellectual roots. $\mathrm{Na}$ condição de estudioso da obra de Thorstein Veblen, principal nome de uma das vertentes radicais das ciências sociais norte-americanas que iriam impressionar o autor de $A$ elite do poder (1956), Tilman assumiu um ponto de partida privilegiado para avaliar o en- raizamento histórico de Mills na tradição de pensamento radical nos Estados Unidos. Considerando tão somente os trabalhos que se dedicam ao conjunto mais global da obra de Mills e não se limitam a temas mais específicos de suas investigações sociológicas, cabe mencionar os estudos de Stanley Aronowitz - Taking it big: C. Wright Mills and the making of political intellectuals (2012), cuja maior contribuição talvez tenha sido a de enfatizar a construção de Mills como um teórico social, ajudando a desconstruir sua imagem de mero crítico das tendências hegemônicas da sociologia norte-americana -, e o de A. Javier Treviño, The social thought of C. Wright Mills (2012). Este último desconstrói criticamente a pesquisa de Mills sobre os imigrantes porto-riquenhos nos Estados Unidos, identificando alguns elementos de sua visão estereotipada sobre a América Latina. Por fım, seria indispensável informar que John H. Summers (2006; 2007; 2008a; 2008b) realizou investigações exaustivas de caráter historiográfico sobre dimensões particulares da trajetória intelectual de Mills, nas quais se destaca o balanço bibliográfico até agora mais completo de sua fortuna crítica, sendo também responsável por compilações de textos do autor (SUMMERS, 2008c), alguns dos quais artigos de jornais de difícil acesso e, por isso, quase inteiramente inéditos.

0 terceiro conjunto de textos sobre Mills, que aqui completaria a presente classificação preliminar de sua fortuna crítica, não constitui propriamente um momento novo, mas uma divisão temática por assuntos mais específicos de suas áreas de pesquisa ou relativa a passagens decisivas de seu itinerário acadêmico e político. São, nesse sentido, trabalhos mais voltados para aspectos e temáticas particulares da produção sociológica do autor ou para situações 
mais localizadas de sua história de vida. Seria desnecessário e impossível listar as mais de cinquenta referências bibliográficas pesquisadas, dentre livros, capítulos de livros e artigos. Por isso serão destacados apenas aqueles trabalhos cujos conteúdos foram até agora analisados pelo autor do presente artigo, tratando-se de uma pesquisa em andamento. Essa rápida seleção se baseia, contudo, na relevância acadêmica e efetiva contribuição para o entendimento da produção sociológica de Wright Mills. No campo da sociologia política, um importante balanço das contribuições originais de Mills a esse campo de investigações pode ser encontrado em Andreas Hess (1995); John D. Brewer (2003) utiliza a perspectiva teórica traçada por Mills em A imaginação sociológica (1959) para compreender os fenômenos da violência na Irlanda do Norte e África do Sul; o livro $C$. Wright Mills and the criminological imagination, organizado por Jon Frauley (2015), reúne uma série de artigos que tematizam o uso analítico da noção de imaginação sociológica em pesquisas empíricas concretas na área da criminologia; diversos estudos altamente especializados sobre a obra de Mills foram reunidos em The Anthem Companion to C. Wright Mills, organizado por Guy Oakes (2016); Javier Treviño (2017) possui um trabalho a respeito da visão política de Mills sobre Cuba; por fim, Keith Kerr (2015) reflete sobre as contribuições atuais de Wright Mills para as ciências sociais contemporâneas, argumentando que já em fins dos anos 1950 e início dos 60 a visão de futuro do autor antecipou processos históricos, políticos, culturais e sociais associados à noção de pós-moderno.

A lista de referências citada, relativa à fortuna crítica de Wright Mills, não se pretende exaustiva, tendo sido selecionados apenas alguns dos títulos mais significativos em termos de seu caráter exemplar ou representativo de um dos três momentos em que foi dividido o estado da arte até agora realizado sobre o autor. Levando-se em consideração que essa classificação se faz provisória, referências igualmente importantes foram deixadas de lado pelo único e exclusivo motivo de se evitar estender em demasia a exposição do presente tópico.

No que diz respeito ao assunto propriamente dito do presente artigo, a sociologia pragmatista de Wright Mills e seus pontos de contato com o interacionismo simbólico e a Escola de Chicago, algumas referências já apontam o diálogo crítico entre o autor e tais correntes políticas e epistemológicas da filosofia e das ciências sociais norte-americanas. 0 livro de Robert G. Dunn (2018), Toward a pragmatist sociology: John Dewey and the legacy of C. Wright Mills, constitui uma importante contribuição para compreender como o pragmatismo influenciou as concepções de Mills sobre as relações entre fato e valor, teoria e prática, nas ciências sociais, apontando suas raízes comuns com a Escola de Chicago, a visão democrática de Dewey e a psicologia social de George Herbert Mead. Além disso, o primeiro capítulo considera como a tradição sociológica de Chicago, predominante até meados da década de 1930 nos Estados Unidos, se voltava contra as tendências formalistas de teorização abstrata e sofisticação metodológica quantitativa hegemônicas entre os anos de 1940, 50 e 60. As afinidades eletivas - mediadas pela influência teórica comum de Mead -, entre a Escola de Chicago e as críticas de Mills à teorização geral de Parsons e ao mero acúmulo de dados empíricos pelo emprego de métodos quantitativos altamente sofisticados, são bastante significativas. A sociologia de Chicago, es- 
tando ligada a movimentos progressistas, democráticos e radicais de reforma social, seria substituída por um tipo de prática nas ciências sociais ligado aos interesses de política externa e interna de órgãos governamentais dos Estados Unidos e suas grandes corporações multinacionais.

As visões comumente aceitas de Mills, ora para uns como weberiano, para outros ora como marxista, foi contestada de forma ricamente documentada por Tilman (1984) com o argumento de que suas raízes ideológicas mais permanentes devem ser buscadas na tradição de pensamento radical norte-americano, em especial Veblen, Dewey e, com muito menor influência, Mead. À parte a discordância quanto à minimização da presença formativa da psicologia social meadeana, pode-se perceber pela leitura do livro de Tilman como o ativismo pragmático de Dewey moldou a concepção de teoria sociológica em Mills, caracterizada por um forte empenho em desenvolver a esfera da atuação prática do sociólogo-intelectual a partir da distinção entre uma sociedade de público e uma sociedade de massas. Aronowitz (2012), por sua vez, ao tratar das origens pragmatistas de Mills, irá representá-lo, sobretudo, como um sociólogo do conhecimento, destacando em especial suas críticas a Mannheim em termos da ausência de uma teoria da linguagem no autor de Ideologia e utopia (1986), capaz de estabelecer a compreensão dos vínculos existentes entre mente e contexto social. " 0 argumento central de Mills é que está faltando na análise de Mannheim sobre os determinantes sociais do conhecimento é uma consideração da linguagem, a qual, para Mills, constitui a ligação vital entre mente e sociedade" (ARONOWITZ, 2012, p. 33). Trata-se de uma contribuição relevante por demarcar a relevância específica das presenças da sociologia mannheimiana do conhecimento e da filosofia da linguagem do pragmatismo norte-americano - influências essas também atuantes na Escola de Chicago -, na construção inicial das posições teóricas e metodológicas de Wright Mills. No caso de Treviño (2012), todo o terceiro capítulo de seu livro será dedicado à reconstrução da psicologia social de Mills, cujos elementos teóricos e conceituais emergem do diálogo entre Mead, Freud, Marx e Weber. Nesse capítulo, Treviños irá se debruçar sobre o livro Caráter e estrutura social (1973), publicado originalmente em 1953 por Mills em colaboração com seu amigo Hans Gerth, alemão radicado nos Estados Unidos e professor da Universidade de Winsconsin. Por fim, o texto introdutório à coletânea de trabalhos de Wright Mills da coleção Grandes Cientistas Sociais, escrito por Heloísa Rodrigues Fernandes (1985, p. 19-24), consta como a primeira referência brasileira a apontar as relações entre as concepções políticas liberais e democráticas do autor e o conteúdo de sua tese de doutorado sobre sociologia e pragmatismo.

Os trabalhos anteriores são ricos em apontar as influências e afinidades recíprocas entre a sociologia pragmatista de Mills, a Escola de Chicago e o interacionismo simbólico ${ }^{4}$. Esta última corrente, apesar de não

4. Sobre a variedade do interacionismo simbólico, ver Bernard N. Meltzer et al., Symbolic interactionism: genesis, varieties and criticism, Boston, London and Henley, Routledge \& Kegan Paul, 1975. Os autores apontam, no mínimo, quatro variedades de interacionismo simbólico como as Escolas de Chicago e a de Iowa, o método dramatúrgico de Goffman e a etnometodologia de Garfinkel, podendo-se questionar, contudo, a identificação stricto sensu dessas duas últimas tendências como interacionistas simbólicas. 
se caracterizar como uma vertente teórica una e indivisível nas ciências sociais, possui suas origens intelectuais mais imediatas nas grandes figuras precursoras ou fundamentais da Escola de Chicago, dentre as quais William James, Charles H. Cooley, John Dewey, George H. Mead, William Thomas e Robert Erza Park. Do mesmo modo, a própria sociologia de Chicago não pode ser encarada como uma escola de pensamento consensual e homogênea (BECKER, 1999; JOAS, 1999). A insistência da perspectiva interacionista na compreensão do sentido simbólico da ação humana, cujos significados são construídos nos processos sociais de modo a moldar o comportamento dos indivíduos, possui raízes nos métodos de pesquisa das distintas tradições sociológicas de Chicago. Tomado como o principal representante do interacionismo simbólico, Herbert Blumer irá privilegiar a utilização de métodos e técnicas de observação tais como "histórias de vida, autobiografias, estudos de caso, diários, cartas, entrevistas (especialmente as de tipos livres e não-dirigidas) e, mais importante, a observação participante" (MELTZER et al., 1975, p. 58), pois defende que a "introspecção simpática” é a abordagem mais adequada para se alcançar o significado profundo dos sentimentos experienciados pelo ator social. A sociedade não seria uma realidade objetiva coexistindo ao lado dos indivíduos e os sentidos que estes atribuem às suas ações. Os processos sociais confor- mam os sentidos das ações dos agentes sociais e vice-versa. As pesquisas sociológicas de Wright Mills incorporam esse legado teórico e metodológico.

Há semelhanças no uso dos métodos de pesquisa entre a perspectiva sociológica de Mills, a Escola de Chicago e o interacionismo simbólico. Os livros $A$ elite do poder (1956) e White Collar (1951) estão repletos de estudos de caso, entrevistas, histórias de vida e, inclusive, observação participante. Porém, não se encontram apenas afinidades em termos de abordagens metodológicas e métodos de pesquisa. Mills estava interessado, sobretudo, no modo como a definição da realidade pelos indivíduos conforma os próprios processos sociais e, por fim, como a vida das pessoas estaria sendo afetada pelos contextos mais globais. Essa seria uma faceta que possui em comum com o interacionismo simbólico oriundo da Escola de Chicago, o qual terminava por conduzir a uma sociologia da vida cotidiana e a um enfoque especialmente voltado para o conhecimento de senso-comum ${ }^{5}$. Mills vai além, contudo, e situa a prática social dos agentes em contextos estruturais mais amplos, reconstruídos como estruturas de poder da sociedade envolvente e suas múltiplas esferas sociais da política, economia e cultura. É nesse sentido que seus trabalhos de investigação conduzem a sínteses entre as ações humanas, de grupos ou indivíduos, processos sociais e padrões estruturais. Em

5. Uma demonstração mais sistemática das afınidades entre as investigações sociológicas de Mills e o interacionismo simbólico exigiria uma reconstrução rigorosa de passagens significativas dos dois livros acima apontados como exemplos, bem como de outras de suas pesquisas. Na introdução à tese de doutorado de Wright Mills publicada como livro, Horowitz (1966) elabora um conjunto de argumentos demonstrando como a filosofia pragmatista norte-americana se encontra presente em cada uma das produções sociológicas do autor. Para matizar melhor a hipótese aqui sustentada, a ponte entre Mills e o interacionismo simbólico pode ser buscada em suas raízes teóricas e filosóficas compartilhadas nas variações internas do pragmatismo norte-americano. 
sua volumosa obra Caráter e estrutura social (1973[1953]), essa tentativa de síntese teórica mais geral recebe alguns avanços e o livro poderia ser revisitado sob tais indícios. Os intérpretes de Mills têm atentado principalmente para as influências da filosofia pragmatista em suas investigações sociológicas como elementos que ajudam a explicar a originalidade de suas contribuições teóricas. Ou seja, isso ajudaria a explicar sua posição como representante de uma específica orientação sociológica, localizando-o em suas diferenças e aproximações com outras correntes como o estrutural-funcionalismo então hegemônico nos Estados Unidos. Mas não eleva Mills ao mesmo status de um Parsons, o de alguém que teria algo a dizer sobre uma síntese de tipo teórico mais geral na sociologia e nas demais ciências sociais. Com exceção de valiosas sugestões de Gabriel Cohn (2013), a produção acadêmica de Mills não seria questionada em termos de suas possíveis contribuições para avançar no refınamento de sínteses teóricas, conceituais, metodológicas e epistemológicas na sociologia.

Talvez o próprio Mills seja um dos responsáveis por tal situação, pois em seu famoso apêndice "Sobre o artesanato intelectual” de A imaginação sociológica (1969[1959]), iria tachar como enfadonhas todas discussões teóricas e metodológicas tomadas como um fim em si mesmo. Podese, por outro lado, argumentar que a razão principal pelo apagamento dessa sua provável contribuição para a construção teórica da sociologia esteja nas disputas hegemônicas de poder entre diferentes tradições das ciências sociais norte-americanas, com fortes repercussões internacionais. Exemplo disso seria a própria publicação de $A$ imaginação sociológica na Argentina, prefaciado por Gino Germani, o representante mais original e inventivo da teoria da modernização na América Latina, responsável pela inovação num contexto periférico dos elementos teóricos e conceituais da sociologia parsoniana. Germani procura amenizar o teor das críticas de Mills ao chamado "empirismo abstrato", pois se tais questionamentos deteriam seu verdadeiro sentido no contexto da história da sociologia nos Estados Unidos, "as críticas ao 'empirismo abstrato' só fariam sentido se já houvesse, na região [América Latina], uma tradição assentada de pesquisas empíricas - o que, em seu entender, não seria o caso" (BRASIL JUNIOR, 2013, p. 65). Em oposição às tradições ensaístas do pensamento social latino-americano, Germani defendia a rotina científica da construção da sociologia na região aliada ao labor de refinamento conceitual, à moda de Parsons, e pesquisas empíricas sistemáticas, em geral associados a métodos quantitativos sofisticados.

0 mainstream da sociologia norte-americana estava à época representado pela combinação da teorização geral com as pesquisas quantitativas. Isso ocorria tanto nos Estados Unidos, como em países submetidos à sua esfera de influência. Um estudo mais amplo da fortuna crítica de Wright Mills deve levar em conta as disputas hegemônicas no campo cultural entre diferentes tradições da sociologia norte-americana. Ao ter sido influenciado pela Escola de Chicago na sua formação acadêmica na Universidade do Texas, Mills irá redirecionar essa orientação inicial pelo confronto crítico com outras correntes de pensamento que se fizeram presentes na história das ciências sociais nos Estados Unidos, tais como a sociologia weberiana. A partir desta, por exemplo, Mills desenvolverá a perspectiva do conflito e suas penetrantes análises sobre o fenômeno burocrático, o 
marxismo frankfurtiano e, inclusive, seu treino na pesquisa empírica sistemática em sua passagem, em 1945, pelo Columbia's Bureau of Applied Social Research (BASR), dirigido por Paul Lazarsfeld ${ }^{6}$. Um trabalho dessa envergadura exigiria um esforço maior de reconstrução da própria história da sociologia nos Estados Unidos, tematizando as disputas por prestígio e poder que deslocaram em meados da década de 1930 a Escola de Chicago, com sua forte inclinação pela pesquisa de campo e observação participante, como principal centro de irradiação do modelo mais influente de investigação sociológica. Essa hegemonia se transferiu para as universidades de Harvard e Columbia, ambas representando dois padrões profissionalmente neutros e científicos de produção acadêmica no campo da sociologia, respectivamente associados ao labor de refinamento teórico-conceitual de Parsons e aos métodos quantitativos de Lazarsfeld. Os deslocamentos entre esses centros como polos hegemônicos de produção nas ciências sociais - não implicando isso um completo apagamento do interacionismo simbólico originário da tradição sociológica de Chicago, que será retomado nos anos 1960 (COSER, 1976; GROSS, 2007) -, devem ser buscados nas transformações internas e externas das estruturas de dominação da sociedade norte-americana. A análise da fortuna crítica em torno da tra- jetória e produção intelectual de Mills, aqui apenas indicada em linhas gerais, deverá levar em consideração os horizontes mais abrangentes da própria história da sociologia norte-americana e suas disputas políticas, teóricas e epistemológicas.

\section{A sociologia do conhecimento de Wright Mills: pragmatismo e interacionismo sim- bólico}

As primeiras referências mais consistentes de Wright Mills à sociologia do conhecimento podem ser encontradas em dois artigos, o primeiro deles publicado na American Sociological Review em 1939 e o segundo no American Journal of Sociology em 1940, respectivamente, com os títulos de "Language, Logic and Culture" e "Methodological consequences of sociology of knowledge"”. Uma rápida consideração desses dois escritos do autor de $A$ imaginação sociológica (1959) ajudará a caracterizar o contexto intelectual de produção das ideias contidas em sua tese de doutorado e sua posição particular no campo da sociologia do conhecimento.

No primeiro desses ensaios, Mills não apenas revela a forte influência de noções como self e o outro generalizado, originárias da psicologia social de George Herbert Mead, como procura explicitamente reorientar a sociologia do conhecimento de

6. Para uma avaliação crítica dessa experiência de Mills no Bureau, ver Jonathan Sterne, "C. Wright Mills, the Bureau for Applied Social Research, and the meaning of critical scholarship", Cultural Studies Critical Methodologies, v. 5, n. 1, p. 65-94, february, 2005.

7. Os referidos artigos foram incluídos na coletânea organizada por Irving Louis Horowitz, Power, politics and people: the collected essays of C. Wright Mills (HOROWITZ, 1963). Tal coletânea foi parcialmente traduzida para o português como Poder e política (MILLS, 1965), porém os dois ensaios mencionados não aparecem na edição brasileira. Uma versão em espanhol de Methodological Consequences of Sociology of Knowledge pode ser consultada em outra antologia organizada por Irving Louis Horowitz (Org.), Historia y elementos de la sociología del conocimiento, Buenos Aires: Eudeba, 1964. 
matriz europeia, citando os escritos clássicos de Mannheim e as obras precursoras de Marx e Engels, no intuito de introduzir uma perspectiva interacionista da linguagem e da cultura. Suas críticas a essa sociologia do conhecimento se dirigem, nesse sentido, à ausência de categorias psicológicas mais precisas. "No presente, a sociologia do conhecimento necessita de uma base psicológica mais adequada da que tem lhe sido dada" (MILLS, 1939, p. 671). Mais adiante irá criticar os marxistas por estabelecerem conexões entre as determinações sociais e a produção de conhecimentos sem uma base psicológica mais aprofundada, pautando-se ainda por uma psicologia da mente de corte tradicional e individualista. "Marxistas não têm procurado traduzir seus termos conectivos categorias psicológicas seguras e não ambíguas”, de modo que a análise ideológica no marxismo se encontraria fundamentada implicitamente em "teorias da mente tradicionais e individualistas” (MILLS, 1939, p. 671-672). Já em relação a Mannheim, dirá que este "encobre a inadequação de sua psicologia com uma vaga e não-analítica "consciência coletiva»" (p. 672). Se tais críticas ao marxismo e à sociologia mannheimiana do conhecimento estariam corretas não é o problema que interessa no presente debate. Bastaria indicar no momento que Mills (p. 672) advoga, como solução analítica, a construção de uma psicologia que incorpore a noção de mente como parte integrante dos processos sociais ${ }^{8}$.
Já no segundo ensaio acima indicado, Mills irá dialogar mais diretamente com a Wissensoziologie europeia, assumindo um ponto de partida que se pode considerar tipicamente norte-americano, o da filosofia pragmatista. 0 debate girava em torno do relativismo e suas consequências para a construção dos critérios de verdade no conhecimento produzido pelas ciências sociais. Ora, se a sociologia do conhecimento constata a determinação política, ideológica e contextual das próprias ciências sociais, o que garantiria a objetividade dessas ciências e quais seriam seus critérios de verdade? A resposta de Wright Mills se direciona para a adoção de um modelo pragmatista de verdade e conhecimento relacional: “As imputações do sociólogo do conhecimento podem ser postas à prova com referência ao modelo de verificação generalizado, por exemplo, por Peirce e Dewey" (MILLS, 1964, p. 149-150). Tal modelo consistia justamente em considerar a localização de um tipo de raciocínio, sua lógica e linguagem, nos seus contextos históricos específicos. “[...] a dimensão 'pragmática' do processo da linguagem (que inclui a dimensão sociológica) está basicamente relacionada com as dimensões semântica e sintática" (1964, p. 148). Completando seu raciocínio um pouco mais adiante, Mills irá dizer que a "linguagem não está livre de influências sócio-históricas” (p. 149). Por isso, as ciências sociais devem se pautar por critérios de verdade que levem em conta a presença dos valores na construção das indagações

8. Importante salientar que Wright Mills escreve este texto na década de 30, por isso sua concepção de linguagem e de psicologia não poderia contar com o refinamento teórico posterior advindo da "virada linguística" das ciências sociais nos anos 60. Nesse sentido, pode-se dizer que falta a Mills instrumentos teóricos mais refınados e as lacunas de seu pensamento podem ser encaradas como limites históricos da própria sociológica cultivada em sua época. 
dos sociólogos e demais cientistas sociais. 0 desafıo metodológico da sociologia do conhecimento seria incorporar o exame dos valores na lógica de produção do conhecimento nas ciências sociais. Nesses termos o próprio Mills irá se posicionar:

Não apenas se deve determinar o conteúdo dos valores das indagações sociais, mas também a forma em que os valores nelas se introduzem, e como condicionam, se assim realmente o fazem, a direção, o caráter completo ou incompleto, e a comprovação dos resultados da investigação. Deste modo podemos ser capazes de formular regras de evidência que impeçam que a exortação inspire nossos resultados. (MILLS, 1964, p. 155)

0 cientista social, preso de modo inextirpável a determinados valores, não poderia deixar de realizar uma autoanálise e perceber em que medida haveria disparidades entre suas palavras e sua ação (MILLS, 1964, p. 155). Mills encerra seu ensaio sobre as consequências metodológicas da sociologia do conhecimento, exigindo das ciências sociais um esforço autocrítico na forma de investigações sociológicas voltadas para desvelar suas próprias determinações ideológicas. Apesar de seu raciocínio recair em algumas circularidades típicas de quem está combatendo o relativismo, falhas essas em que também incorre Mannheim em Ideologia e utopia (1986), a sugestão de que apenas uma sociologia das ciências sociais poderia defınir os critérios de conhecimento e de verdade dessas ciências seria um insight genial ainda hoje distante de uma solução satisfatória nas reflexões epistemológicas do pensamento social contemporâneo. Para Mills, a verdade nas ciências sociais poderia assumir um tom aproximado, por assim dizer probabilístico, muito em conformidade com os padrões da lógica estabelecidos pelo pragmatismo, mas não implicaria uma verdade relativista, única e exclusivamente dependente da posição de que se fala. 0 fato de a verdade ser contextual não implica estar desprovida de objetividade. A sociologia do conhecimento assumiria, nesse sentido, uma função propedêutica em termos epistemológicos, pois serviria de fundamento metodológico para as práticas empíricas de investigação nas ciências sociais ${ }^{9}$.

Já em 1940, Wright Mills detinha um conhecimento acurado dos textos de sociologia do conhecimento de Karl Mannheim, tecendo críticas a este autor a partir de seus próprios pontos de vista pragmatistas. Curiosamente, na sua tese de doutorado escrita em 1942 o nome de Mannheim sequer é mencionado. Apenas podemos observar menções à noção de "estilo de pensamento”, de forte inspiração mannheimiana. Essa noção, central no ensaio de Mannheim sobre o pensamento conservador na Alemanha do século XIX, não parece ser utilizada como um recurso analítico no trabalho de Mills sobre a filosofia pragmatista norte-americana. De igual modo, ele não utiliza fortemente qualquer esquema con-

9. Não seria verdadeira a tese de que Wright Mills e Karl Mannheim seriam relativistas. Os dois combateram o relativismo nas ciências sociais, podendo-se questionar em que medida eles obtiveram êxito. Seria importante mencionar que algumas ideias desenvolvidas nesta parte do trabalho se devem ao exame dos comentários críticos de Irving Louis Horowitz, C. Wright Mills: an American utopian, New York, The Free Press, 1983, p. 117-134. 
ceitual típico-ideal - como procede Mannheim nas suas considerações sociológicas sobre visões de mundo, ideologias e/ou estilos sociais de pensamento -, para reconstruir algo que se parecesse a um estilo de pensamento pragmatista. Mills sequer se preocupa com uma defınição inicial, geral e provisória, que pudesse orientar a investigação das dissensões e variações internas ao próprio pragmatismo norte-americano.

A sua perspectiva de análise, baseada na epistemologia pragmatista, realiza um caminho totalmente oposto. Seria a partir do exame dos processos sociais - focalizados simultaneamente nos níveis macroestruturais da história e da sociedade, de um lado, e microinteracionistas das relações institucionais, profissionais, familiares, políticas, religiosas e de outras esferas da sociabilidade humana, envolvendo inclusive aspectos biográficos das trajetórias de vida dos indivíduos, de outro -, que iria emergir a compreensão das diferenciações internas do pragmatismo norte-americano em seus vínculos concretos com a transformação de contextos sócio-histórico particulares. Nesse sentido, as definições prévias, típico-ideais e provisórias, não seriam necessárias dentro de tal orientação metodológica.

0 diálogo com alguns nomes da filosofia pragmatista norte-americana, em especial William James e John Dewey, será de fundamental importância, não somente para compreender essa construção metodológica de sua sociologia do conhecimento, mas também, e principalmente, para entender o conjunto do pensamento político de Wright Mills. Em outros termos, seus vínculos com a filosofia pragmatista não assumem apenas uma dimensão intelectual, lógica e/ou epistemológica, mas se explicam pelo conteúdo político de suas orientações ideológicas e afınidades com os valores, às vezes idealizados pelo próprio Mills, de defesa da autonomia e liberdade individuais que sustentam a narrativa das origens da democracia nos Estados Unidos. Inclusive, suas críticas à sociedade norte-americana se concentram na constatação da não concretização desses valores, cujos motivos residiriam na apatia política de uma sociedade de massas controlada burocraticamente por um pequeno consórcio de elites, compostas por grandes industriais, políticos de alto escalão e militares de elevada patente. A sociologia do conhecimento de Mills ajudaria, nesse caso, a explicar suas próprias concepções teóricas e metodológicas nas ciências sociais.

Em Sociology and pragmatism: the Higher Learning in America, o autor irá elaborar pela primeira vez de forma mais sistemática as linhas gerais de sua perspectiva teórica e metodológica nas ciências sociais, embora sem assumir de modo explícito seu ponto de vista político radical. Porém, estrutura, história e biografia já seriam aí apanhadas em conjunto dentro de um horizonte pragmatista, em que as ações dos indivíduos e grupos são focalizadas no contexto mais amplo dos processos sociais. Ao mesmo tempo, as reflexões metodológicas se encontram presentes, algumas vezes implicitamente, no andamento da escrita de toda sua tese de doutorado. Para Mills, a sociologia do conhecimento assume um caráter autorreflexivo, como diria no posfácio de seu trabalho escrito em 1943. Ao avaliar seu próprio trabalho de investigação no campo da sociologia do conhecimento, afirma ter estado consciente a todo instante dos problemas epistemológicos com os quais se deparou, sugerindo que as soluções por ele mesmo alcançadas até então talvez não pudessem ser as mais satisfatórias: 
É também opinião do escritor que um propósito como esse [de investigações no campo da sociologia do conhecimento], para se tornar completo, deveria ser acompanhado de todas as maneiras possiveis por uma detalhada autorreflexão metodológica. No presente estágio das pesquisas na sociologia do conhecimento seria necessário que cada tarefa substantiva viesse acompanhada de uma explícita autoconsciência, tanto dos procedimentos detalhados, como das preocupações epistemológicas mais abrangentes. Avanços na sociologia do conhecimento não decorrem apenas de trabalhos substantivos, pois cada parte do trabalho envolve questões metodológicas, de forma que desconsiderá-las nos conduziria ao risco de cruzar fronteiras acadêmicas intelectualmente ultrapassadas. Tanto quanto posso estar consciente disso, não estou de todo satisfeito com a base metodológica e argumentos racionais deste trabalho concreto na sociologia do conhecimento [Mills se refere à sua própria tese de doutorado]. 0 escritor tinha consciência destes problemas e, inclusive, redigiu muitas notas marginais com tais reflexões. A omissão delas no presente trabalho se deve em grande parte à irrelevância de sua exposição $0^{10}$ (MILLS, 1966, p. 466-467).

Mesmo não apresentando o conjunto dessas suas reflexões metodológicas marginais ao objetivo central de seu trabalho, Mills irá elaborar - talvez em alguns momentos sem disso se dar conta inteiramente -, considerações de grande valor teórico e epistemológico, referentes a questões práticas de investigação no campo da sociologia do conhecimento, em algumas passagens cruciais da sua tese de doutoramento, construindo uma armadura conceitual autorreflexiva ao combinar afırmações provenientes de seus próprios procedimentos lógicos de indagação sobre o mundo social - o que lhe permitiria produzir certos tipos de resultado e não outros -, com a crítica destes mesmos métodos de raciocínio. Isso se sente principalmente em algumas de suas rápidas considerações teóricas sobre os pontos de articulação entre estrutura social, processos históricos de larga duração e trajetórias individuais, encontradas aqui ou ali, de maneira esparsa, na sua tese de doutoramento sobre o pragmatismo.

Seria, em especial, nos capítulos das duas primeiras partes da tese de doutorado de Wright Mills sobre o pragmatismo, que tais considerações teóricas se apresentariam de modo mais concentrado e com maior força, tornando mais nítidos os pontos de fuga do desenho metodológico de sua pesquisa. Na primeira parte do livro, o foco recai sobre fenômenos macroscópicos da estrutura social, organizacional, profissional e ocupacional dos Estados Unidos. Tudo isso estaria relacionado a mudanças profundas na divisão social do trabalho e a conflitos entre instituições religiosas e educacionais. Esse seria o pano de fundo de sua compreensão das transformações nos perfis do pessoal docente e de pesquisa nas universidades estadunidenses, com impac-

10. A leitura do posfácio de 1943, isto é, escrito um ano após o término da escrita da tese de doutorado, assume grande importância, pois Wright Mills indica as lacunas de seu trabalho, dentre elas a ausência da investigação do papel fundamental de George Herbert Mead na gênese da filosofia pragmatista, e traça um panorama geral da situação da sociologia do conhecimento naquele momento histórico. 
tos significativos nos horizontes da formação profissional de pesquisadores e professores de filosofia para o ensino superior. 0 pragmatismo se define, sociologicamente, pela defesa de uma postura acadêmica e profissional em oposição ao amadorismo e diletantismo das correntes filosóficas tradicionais. Trata-se do conflito entre um grupo emergente, que se entrincheira no ensino superior em franco processo de institucionalização, e grupos intelectuais tradicionais ligados às instituições religiosas.

Indo mais além em suas exigências de captar a dinâmica complexa da produção do conhecimento, Wright Mills não aprisiona a análise no plano exclusivo dos grandes processos sociais e de transformação das macroestruturas. A sua imaginação sociológica exemplar se volta para o modo como ação e estrutura se retroalimentam, sendo de especial relevância sua análise da composição biográfica do Clube Metafísico, uma associação de intelectuais de distintas extrações sociais e formações profissionais cujos debates dariam origem à filosofia pragmatista. No dizer de Bogomolov, um dos críticos marxistas do pragmatismo norte-americano orientado pelos cânones dogmáticos do materialismo histórico da União Soviética, o "seio materno do pragmatismo foi o 'Clube Metafísico' fundado em 1871, em Cambridge, por um grupo de pensadores de linha semelhante" (BOGOMOLOV, 1979 , p. 22). Os membros do Clube Meta- físico estavam assim distribuídos segundo suas profissões: Charles Sanders Peirce (1839-1914), cientista e filósofo; William James (1842-1910), professor e filósofo; Joseph Warner (1800-1923), advogado; Oliver Wendell Holmes, Jr. (1841-1935), advogado e lecturer $^{11}$; Nicholas St. John Green (1830-1876), advogado e lecturer; Chauncey Wright (1830-1875), cientista e filósofo; John Fiske (1842-1901), historiador, bibliotecário e divulgador científico; Francis Ellington Abbot (1836-1903), religioso freelance e ocasionalmente pastor; John Chipman Gray (1839-1915), advogado e lecturer (MILLS, 1966, p. 114). As origens familiares dos membros do Clube Metafísico também são traçadas pelo autor, como uma espécie de sociologia da vida intelectual, a fim de indicar as influências recíprocas entre a produção do conhecimento filosófico e os contextos sociais cambiantes. 0 ambiente político do referido clube foi o da Guerra de Secessão (1861-1865), que expressou os dilemas do liberalismo norte-americano, dividido entre as pressões políticas para o desenvolvimento capitalista dos Estados do Norte, atuando como substrato material do movimento abolicionista e das tendências unificadoras nacionais, e os interesses dos grandes latifundiários do Sul, os confederados separatistas que poderiam se beneficiar com a manutenção da situação colonial $^{12}$. 0 Clube Metafísico representava um momento de transição, no

11. Palavra que pode ser traduzida também como docente ou professor universitário, porém sem necessariamente possuir atribuições de pesquisador. 0 lecturer estaria vinculado às turmas iniciais de cursos superiores não-graduados (undergraduated). Já o termo Professor diz respeito ao profissional acadêmico que, em termos de qualificação, possui maior experiência e, ao mesmo tempo, realiza atividades de pesquisa, exercendo suas atividades em cursos graduados (graduated) de mestrado e/ou doutorado.

12. Sobre o Clube Metafísico e suas relações com a história dos Estados Unidos, uma bibliografia mais ampla sobre o assunto pode ser obtida na leitura da resenha do livro de Louis Menand, The Metaphysical Club: a story of ideas in America (2001), escrita por Cassiano Terra Rodrigues (2003). 
qual as discussões filosóficas ainda não estavam inteiramente institucionalizadas nos marcos acadêmicos do ensino superior.

Os vínculos sociológicos entre a situação política pós-Guerra Civil nos Estados Unidos e os motivos intelectuais de emergência da filosofia pragmatista, se talvez não tenham sido originalmente estabelecidos por Wright Mills, ao menos expressam na sua tese de doutorado a origem política de suas futuras posições metodológicas nas ciências sociais, dado que a solução aventada pelo pragmatismo, como resposta para os dilemas da democracia norte-americana enfrentados de forma explosiva no conflito separatista, seria - em substituição a essa violência vivenciada -, uma concepção de mundo calcada no livre debate de ideias, na pluralidade de opiniões e nas decisões democráticas. Ao enfatizar que uma das categorias centrais da sociologia norte-americana (ou, mais exatamente, da vertente da sociologia norte-americana com a qual nosso autor se identifica, a do interacionismo simbólico da Escola de Chicago) seria a ênfase nos processos sociais contínuos, a qual, por sua vez, caminharia lado a lado com uma concepção multilateral e pluricausal da história e da sociedade, Mills assume uma postura metodológica que o aproxima dos ideais democráticos de construção da moderna nação estadunidense, então reforçados no contexto da Guerra Civil. Esta herança do pragmatismo foi assumida em oposição ao que Mills (1964, p. 156) considerava ser o monismo causal de certas versões do materialismo histórico ${ }^{13}$.
Em oposição, o autor passa a assumir uma postura pluralista nas ciências sociais, a qual deve ser entendida não apenas em termos teóricos, mas também políticos de defesa dos valores democráticos da liberdade e autonomia individuais.

Aí se apanha a perspectiva ideológica de Wright Mills, evidenciada pelas afinidades eletivas entre seu pensamento sociológico e o pluralismo democrático da filosofia pragmatista norte-americana. Em seus horizontes críticos, tal situação poderia se revelar uma faca de dois gumes já que o pluralismo poderia conduzir ao imobilismo político, algo por ele mesmo rejeitado. Isso, no entanto, apenas revela a riqueza e as tensões características e constitutivas de seu pensamento sociológico. Por outro lado, seriam essas mesmas tensões que Mills procura apanhar na análise da trajetória intelectual dos principais representantes da filosofia pragmatista nos Estados Unidos.

A segunda parte de sua tese de doutorado reconstitui o caminho percorrido por Charles Peirce, considerado por muitos como o fundador do pragmatismo, indicando como suas ações individuais possuem sentido sociológico mais abrangente dentro do contexto histórico de mudanças das estruturas da divisão social do trabalho nos Estados Unidos. Motivado pela urbanização em ritmo acelerado e crescimento exponencial das indústrias, esse processo de divisão do trabalho seria acompanhado de fortes ressonâncias na composição organizacional do ensino superior norte-americano e de acesos conflitos entre visões de

13. Aqui não está em discussão se as críticas e interpretação de Wright Mills sobre o marxismo, típicas de um liberalismo radical-democrático, estariam corretas. Cumpre observar, porém, que as leituras mais aprofundadas de Marx e das tradições marxistas, por parte de Mills, surgem bastante tardiamente. A esse respeito, ver C. Wright Mills, Os marxistas, Rio de Janeiro, Zahar, 1968. Na década de 1930 Mills já tinha conhecimento dos textos de Marx, mas esse aprofundamento só ocorrerá nos anos 50. 
mundo religiosas e concepções modernas mais secularizadas do mundo natural e da existência humana.

As duas primeiras partes da tese de doutorado de Wright Mills se complementam e nelas se pode encontrar o essencial de seu roteiro metodológico para as investigações sociológicas dos processos de produção do conhecimento, nesse caso concreto o da emergência histórica do pensamento pragmatista norte-americano. A reconstrução da estrutura social e da organização institucional do ensino superior em mudança nos Estados Unidos de fins do século XIX, avançada na primeira parte, não foi realizada dentro de uma perspectiva meramente estrutural-funcionalista e objetivista. Os tipos humanos, seu caráter e personalidade, são também essenciais na descrição da estrutura social, pois será o conjunto articulado de suas ações individuais a força motriz das transformações mais gerais, no curto, médio e longo prazos, da sociedade envolvente. 0 indivíduo não é um dado apartado da estrutura. É nesse sentido que as tensões existenciais na trajetória de vida de Charles Peirce, no que elas possuem de vínculo sociológico com as tensões constitutivas de uma estrutura social em mudança, se tornam presentes na reconstrução de seu estilo particular de pensamento, produzido em oposição à forte impregnação religiosa das correntes filosóficas tradicionais nos Estados Unidos. Mills, porém, não opera com a noção de "estilo de pensamento" como um tipo-ideal previamente construído com base em trabalhos historiográficos e outras fontes. A caracterização dos estilos de pensamento dos pensadores analisados na tese - Peirce, James e Dewey - emerge diretamente dos esforços concretos da investigação, e isso se torna tão evidente que a própria forma de exposição do livro parece seguir passo a passo as etapas de reconstrução das ideias filosóficas de cada um desses três pensadores, não havendo quase nenhuma distinção entre as lógicas da investigação e de exposição. Essa seria uma exigência metodológica talvez bastante particular da sociologia do conhecimento, pois não haveria outra maneira de incorporar na análise os processos sociais focalizados em seus fluxos contínuos de transformação e nas suas diversas especificidades de situação e contexto sociais.

Um breve resumo das duas primeiras partes da tese de doutoramento de Wright Mills possibilitará uma descrição mais detalhada de suas perspectivas teóricas e metodológicas, em termos de sugestões práticas de investigação no campo da sociologia do conhecimento. Deixaremos de lado uma discussão mais detida sobre as trajetórias de vida e concepções filosóficas de William James e John Dewey, tais como contidas na segunda e terceira partes do livro. 0 enfoque aqui restrito apenas à segunda parte da tese de doutorado, pertinente a Charles Peirce, se tornou uma necessidade porque tal pensador ainda vivenciava um momento de transição entre as antigas e tradicionais correntes filosóficas nos Estados Unidos e a escola pragmatista norte-americana, que produziu uma filosofia de cunho moderno, muito mais atenta ao ethos profissional da especialização acadêmica. Nesse sentido, as tensões constitutivas do pensamento de Peirce deterão o poder de expor, com maior ênfase, os dilemas metodológicos de Mills e as soluções provisórias por ele sugeridas a fim de superá-los. No entanto, seria preciso mencionar que esse não foi o filósofo pragmatista que mais influenciou o nosso autor. William James e, principalmente, John Dewey deterão uma presença política ainda mais importante no pensamento de 
Wright Mills, em particular no modo como este pensaria as relações entre teoria e prática nas ciências sociais.

No capítulo primeiro da Parte I, intitulado "Divisão do trabalho, religião e instituições educacionais”, Mills estabelece o ponto de partida da sua pesquisa. "Nosso problema mais genérico consiste em explicar as relações entre um tipo de filosofia, o pragmatismo, e a estrutura social americana, 'entre' filosofia e sociedade” (MILLS, 1966, p. 35). Essa estrutura social é caracterizada, desde a Guerra Civil (1861-1865), pela expansão industrial e consequentes mudanças na composição ocupacional com o surgimento de novos grupos profissionais. 0 foco de Mills, no entanto, se volta especificamente para as instituições educacionais de ensino superior. Estas últimas realizam as devidas mediações, especificando as relações entre "a mudança da estrutura social e as transformações das doutrinas filosóficas” (p. 35). Fora dos muros das universidades também havia movimentos intelectuais, grupos e indivíduos produzindo pensamentos filosóficos tais como o transcendentalismo e o movimento de Saint Louis $^{14}$. Tais movimentos não eram liderados ou constituídos por acadêmicos profissionais; ao contrário, o pragmatismo tinha como maiores protagonistas acadêmicos por excelência (p. 36), "estudantes pós-graduados e mais tarde professores em universidades americanas”. As mudanças na estrutura social, em termos de divisão do trabalho e de uma nova composição profissional, são vivenciadas na universidade como um processo de secularização, de emergência da cul- tura científica e abertura no que diz respeito à possibilidade de escolha de variadas especializações acadêmicas. 0 sistema baseado na autoridade dos estudos clássicos passa, progressivamente, a ser substituído por um sistema eletivo, baseado na livre escolha dos estudos. Mills irá apontar essas mudanças nos seguintes termos:

0 crescimento e a complexidade das divisões do trabalho, e sua consequente especialização, significavam [...] o sistema eletivo. [...] Os argumentos essenciais para o sistema eletivo tinham sido elaborados antes da Guerra Civil, mas só durante a última metade do século XIX a proliferação de ocupações tornou o sistema eletivo imperativo para a sobrevivência e crescimento das escolas e universidades. R. Freeman Butts [...] indica que durante a última metade do século XIX elas transitaram do princípio prescritivo da autoridade para o eletivo, para novos assuntos; dos "estudos clássicos e tradicionais" para "as ciências, história e línguas modernas" (MILLS, 1966, p. 40).

Tais mudanças de orientação não ocorreriam sem conflitos com as antigas concepções religiosas de mundo, as quais ainda impregnavam fortemente o pensamento filosófico norte-americano. 0 pragmatismo surge nesse momento de transição e isso explica, em parte, os violentos contrastes entre religião e ciência no interior dessa corrente de pensamento filosófico. Na verdade, podemos encontrar aí um traço biográfico do próprio Mills nos seus conflitos

14. Aqui não está em discussão se as críticas e interpretação de Wright Mills sobre o marxismo, típicas de um liberalismo radical-democrático, estariam corretas. Cumpre observar, porém, que as leituras mais aprofundadas de Marx e das tradições marxistas, por parte de Mills, surgem bastante tardiamente. A esse respeito, ver C. Wright Mills, Os marxistas, Rio de Janeiro, Zahar, 1968. Na década de 1930 Mills já tinha conhecimento dos textos de Marx, mas esse aprofundamento só ocorrerá nos anos 50. 
de juventude com a religião e o conservadorismo de seu local de nascimento, o Texas. Para ter uma ideia deste acentuado conservadorismo político, Irving Louis Horowitz, autor de uma das primeiras biografias mais completas de Wright Mills, esclarece que a legislação do estado do Texas proibia a contratação para trabalharem, como funcionários da universidade, pessoas que não acreditassem em "Deus como Ser Supremo e Criador do Universo" (HOROWITZ, 1983, p. 16). De origem católico-romana, nosso autor irá se declarar algum tempo depois agnóstico e isso o colocava em confronto direto com suas raízes sulistas e texanas. Apesar do conservadorismo dominante na Universidade do Texas, seria justamente aí que ele iria travar seu primeiro grande contato com a tradição sociológica da Escola de Chicago e sua visão política progressista no campo das ciências sociais. Ao romper com as tradições religiosas de sua família, Mills quebrou barreiras e rompeu com o destino que lhe estava traçado pelas suas origens sociais. Há uma íntima ligação entre a biografia do autor e suas posições políticas, teóricas e metodológicas no campo das ciências sociais, em especial a fé inquebrantável de que o indivíduo autônomo poderia intervir nos rumos de sua própria sociedade. Nesse sentido, suas críticas se dirigiam às modernas sociedades de massas baseadas no mercado, produtoras de indivíduos apáticos e alienados, não cidadãos, mas verdadeiros "robôs alegres", concentrando as mais importantes decisões que afetam a coletividade nas mãos das elites do poder. A sociologia do conhecimento de Wright Mills, ao acentuar metodologicamente as relações entre biografias, história, sociedade e construção do saber, reforça suas convicções políticas de defesa da liberdade e autonomia dos indivíduos, de modo que estes possam enfrentar seus problemas particulares como questões mais gerais de suas respectivas épocas históricas.

A crença na possibilidade de mudar os rumos da própria vida, influenciando nos acontecimentos históricos e na sociedade, talvez tenha levado à outra característica crucial dos horizontes metodológicos de Mills na sociologia do conhecimento. Para cada tipo de estrutura e organização sociais, há tipos de homens e mulheres cujas ações são capazes de intensificar as transformações em curso. Nesse sentido, os capítulos da primeira parte da tese de doutorado de Mills não se limitam a apresentar dados e estatísticas de crescimento das instituições educacionais, de surgimento de novas categorias ocupacionais e profissionais, de cursos pós-graduados em diferentes áreas do conhecimento, bem como da quantidade e variedade de novos estudantes no ensino superior. É certo que Mills dominava os métodos e técnicas da pesquisa quantitativa, uma perspectiva que ele iria criticar bem mais tarde, no ano de 1959 em A imaginação sociológica, como um imperdoável "empirismo abstrato". Ao lado desse enfoque mais geral das estruturas em termos quantitativos, ele incorpora de maneira bastante original biografias, histórias de vida e documentos pessoais. Ao analisar as mudanças nas instituições educacionais, ele se preocupa fundamentalmente com os tipos de indivíduos responsáveis por essas transformações, a exemplo dos "administradores educacionais" e os "ricos filantropos" (MILLS, 1966, p. 37), estes últimos atuando como verdadeiros mecenas ao financiarem as novas universidades. Os títulos dos demais capítulos da primeira parte - Tipos de homens e as Novas Escolas (cap. 2), Escolas Pós-Graduadas e Profissionalização (cap. 3), 0 pessoal da filosofia americana (cap. 4) 
e Composição biográfica do Clube Metafísico (cap. 5) - revelam um acentuado esforço de aproximar a investigação sociológica do conhecimento de um exame da prática real, concreta, dos indivíduos e grupos que se empenham em influenciar nas decisões políticas que afetam suas próprias vidas e os rumos de suas sociedades.

A descrição e interpretação dos debates no interior do Clube Metafísico são exemplares do método de análise de Wright Mills, pois a composição biográfica aí montada recolhe os elementos conceituais que irão configurar os choques de estilos de pensamento entre os integrantes desse grupo diversificado de intelectuais. 0 exame sociológico do Clube Metafísico corresponde à transição entre a focalização dos grandes processos históricos de mudança das estruturas sociais e as trajetórias individuais. Não se pode esquecer que o pensamento filosófico norte-americano também vivenciava um período de fortes mudanças, por isso o confronto de perspectivas se dará, no interior do próprio Clube Metafísico, entre ciência e religião, realismo e nominalismo, lógica e metafísica, ciências naturais e sociais, filosofia e religião, sendo que alguns membros participantes das reuniões do grupo não podem ser caracterizados exatamente como pragmatistas. Alguns deles chegavam a professar ideias contrárias a algumas das teses centrais do pragmatismo. Francis Ellington Abbot, por exemplo, parecia mais preocupado em preservar suas crenças religiosas, no confronto com a ciência, criando aquilo que chamaria de teísmo científico (MILLS, 1966, p. 86-92). Os períodos de transição acentuam as tensões entre os projetos individuais e a estrutura social, por isso a trajetória intelectual de Charles Peirce se presta, pela intensidade dos contrastes, a evidenciar al- guns aspectos metodológicos da sociologia do conhecimento aqui em debate. Apesar de ter lançado as bases da filosofia pragmatista, Peirce não atuará como um acadêmico profissional e muito menos manterá um público fiel, receptivo para seus trabalhos - o que não seria o caso para filósofos pragmatistas mais estabelecidos, a exemplo de James e Dewey. Ora, uma das fontes da força do pragmatismo esteve na sua institucionalização acadêmica. Peirce era uma espécie de precursor da filosofia pragmatista e também um outsider no universo acadêmico. Nesse sentido, a sua trajetória reflete os embates do pragmatismo para se consolidar como uma alternativa diante das limitações das correntes filosóficas tradicionais nos Estados Unidos.

As tensões no pensamento de Peirce se refletem nas suas ações concretas, com tanta maior força quanto os debates internos no Clube Metafísico lhe pressionam a tomar posições intelectuais contrárias ao de seus interlocutores. Pedindo licença a uma noção bourdieusiana e utilizando-a sem muita exatidão, esse grupo funcionava como um campo intelectual em miniatura. As diferenças de ideias no pragmatismo e dentro do Clube Metafísico se devem, segundo Mills (1966, p. 85), a "variações de posições políticas e suas inúmeras misturas com outras afiliações intelectuais, crenças e costumes”. As ações de Peirce são respostas não apenas aos membros individuais do Clube, mas também às diferentes situações de vida que eles representavam na estrutura social. Nesse sentido, os elementos das críticas que Peirce direciona a seus companheiros de infindáveis discussões filosóficas constituem a tessitura conceitual de seu estilo social de pensamento. Sem a focalização dessas ações concretas, a reconstrução de um estilo de pensamento 
não passaria de uma mera abstração sem vida. Nesse terreno, Mills supera as construções de tipos ideais, de um lado, e rejeita a mera constatação das "homologias estruturais” entre realidade social e consciência, de outro, propondo um método de análise que focaliza as ações e ideias concretas dos indivíduos atuantes em suas escolhas e decisões significativas face ao mundo social - escolhas essas realizadas na maioria das vezes de modo não plenamente consciente pelos indivíduos e grupos sociais. Isso não significa tão somente afirmar que o interesse guia nosso conhecimento num plano filosófico mais geral, mas implica analisar como as relações entre conhecimento e interesse se desenvolvem efetivamente como um processo de cunho social e político.

0 objetivo da sociologia do conhecimento, em outras palavras, seria estabelecer relações entre produção do saber e padrões sociais de ação. “[...] encontramos (no caso de Charles Peirce) um vínculo direto de um pensador abstrato e seus conceitos com seus padrões de ação" (MILLS, 1966, p. 142). Peirce atuava como um cientista prático de laboratório e organizador de associações científıcas, de modo que tal atuação forjou de alguma forma sua maneira de pensar filosoficamente. Ao lado deste ethos científico, que se tornou o pano de fundo de suas reflexões filosóficas, o fundador do pragmatismo elaborava suas ideias a partir de um conjunto complexo de influências provenientes de uma estrutura social em processo de transformação, mediadas por sua origem familiar, seu círculo de interlocutores mais imediato, o Clube Metafísico, e os públicos externos por ele confrontados no ato mesmo da escrita e da produção de novos saberes. Em termos de análise, Mills concebe essa rede de interações entre agentes sociais a partir da noção meadeana do “outro generalizado”, revelando o quanto sua sociologia do conhecimento deve à psicologia social de orientação pragmatista. Essas influências teóricas e metodológicas se tornam muito patentes nas considerações de Mills sobre o público externo de Peirce, que se caracteriza por uma natureza predominantemente científica:

[...] suas audiências externas efetivas - e como ele as internalizou como um outro generalizado a partir de conversações com seu pai e com Chauncey Wright no centro do Clube Metafísico de Peirce, inclusive suas invectivas contra o público filosófico de Harvard ${ }^{15}$ eram cientificas. A mente delas [dessas audiências externas] foram construídas pela participação na prática da ciência. Era com elas que ele estava pensando; era para elas que ele estava escrevendo. 0 completo significado do que ele pensava repousa nas mentes delas, bem como na sua própria. Comunicação viva operando em seu pensar, a audiência funcionava como seu outro generalizado, conformando sentidos e hábitos de ação de uma prática científica (MILLS, 1966, p. 142).

As teorias e categorias do pensamento de Charles Peirce passam a ser confrontadas com suas experiências ocupacionais de modo a explicar sociologicamente, de um lado, os determinantes sociais de suas ideias filosóficas e, de outro, o próprio pro-

15. Charles Peirce lecionou filosofia da ciência em Harvard entre 1864 e 65 (MILLS, 1966, p. 133). Seus cursos eram de difícil compreensão e, como uma espécie de outsider na academia, ele se contrapunha ao ensino filosófico então predominante nos Estados Unidos. 
cesso sócio-histórico e político de construção do pragmatismo. Os elementos do pensamento de Peirce só serão selecionados, no conjunto da análise, se apresentarem relações significativas com tais propósitos sociológicos específicos. "A área do pensamento de Peirce que mais claramente se relaciona com os aspectos centrais de suas experiências ocupacionais é sua teoria da dúvida e da crença, sua visão sobre o caráter e função da indagação, seu pragmatismo" (MILLS, 1966, p. 144). Na tentativa de explicar as diferenças de concepções filosóficas no interior do pragmatismo, o método de abordagem que Mills utiliza em relação a Peirce também será seguido no âmbito de suas considerações sociológicas sobre os pensamentos de James e Dewey ${ }^{16}$. 0 núcleo central do método de Mills consistia, enfim, em relacionar cada dimensão de um determinado estilo social de pensamento suas categorias, conceitos, ideias, justificativas e racionalizações, bem como maneiras específicas de sentir, pensar e agir -, com aspectos sociologicamente relevantes da estrutura social então selecionados durante o processo da pesquisa. Os passos da análise sociológica de Mills sobre a produção filosófica de Peirce se encontram descritos minuciosamente na passagem a seguir:
Eu me aproximei do "pragmatismo" de Peirce inicialmente em termos do papel da indagação. Há várias doutrinas de Peirce a partir das quais podemos reunir o que ele concebeu como sendo o propósito geral do contexto da indagação. 0 mais importante é a sua discussão da "dúvida e crença", em seguida é "a sua máxima pragmática”. Em ambos estes contextos emergem os conceitos de "ação", ou de "hábito", estando também relacionados com uma teoria do significado e com a finalidade da indagação. De ordem a apreender o completo significado e orientação desses vários conceitos, devemos examinar certas observações de Peirce sobre o "prático" e o "útil" em suas relações com a indagação e o conhecimento. Será necessário também examinar seu "realismo" e a ênfase sobre a "sociabilidade" e o "sentimento", bem como suas fortes reações contra o "individualismo" e "a filosofia da necessidade". Esta é a ordem pela qual iremos proceder. São esses os focos que irão exaurir nosso interesse pelos aspectos centrais do pragmatismo de Peirce. Em cada um destes modos de formulação deveremos notar a verificação de uma característica central em Peirce: o seu pragmatismo surgiu de sua dupla ocupação como cientista prático, aliada à sua contínua posição de outsider filosófico. Por exemplo, será im-

16. Por razões de espaço e, principalmente, pelo fato de os critérios metodológicos elaborados por Wright Mills no caso de Peirce se repetirem, no que concerne ao estudo sociológico dos outros dois pensadores, será aqui omitida a exposição das partes III e IV do livro. Cumpriria observar apenas que o mesmo itinerário da análise será utilizado, iniciando-se com um enfoque biográfico de cada um dos filósofos pragmatistas para depois apresentar as categorias, conceitos e métodos de seus respectivos pensamentos mais diretamente relacionados com as transformações históricas da estrutura social. A terceira parte se encontra assim dividida: William James (Cap. 11); Três vocabulários da prática social (Cap. 12); A polarização entre ciência e religião (Cap. 13); Liberalismo psicológico (Cap. 14). Já a parte mais extensa do trabalho, sobre John Dewey, se encontra separada entre os seguintes capítulos: John Dewey (Cap. 15); Hull House e consequentes escritos (Cap. 16), no qual se tematiza a aproximação de Dewey com movimentos filantrópicos de reforma social; 0 público leitor de John Dewey (Cap. 17); Profissionalização do ensino (Cap. 18); 0 público filosófico e ascensão profissional (Cap. 19); Significados e crenças em Dewey (Cap. 20); Modulações da ação (Cap. 21); Liberdade e cultura (Cap. 22); Psicologia Social: modelo para liberais (Cap. 23). 
putando a combinação dessas duas posições a um determinado estilo de pensamento que poderemos compreender suas concepções de "dúvida”, "crença” e "indagação" (MILLS, 1966, p. 145).

0 esquema analítico da sociologia do conhecimento de Mills se baseia nos pressupostos teóricos (1) de que nosso pensamento se constrói em estreita relação com diversos aspectos diferencialmente situados da estrutura social - ponto esse que o aproxima teoricamente da Wissensoziologie europeia em geral -, e (2) de que o caráter prático do conhecimento nos termos da "máxima pragmática" - segundo a qual o significado total de nossas concepções reside na totalidade de suas consequências práticas antecipáveis e concebíveis -, canaliza as conclusões e resultados concretos das ações cognitivas a partir das influências dos valores, hábitos e crenças dos agentes sociais responsáveis pela produção e reprodução do saber coletivamente construído. Ou seja, para Mills a produção de conhecimento sobre o mundo social envolve ideologias e visões de mundo que não podem ser desconsideradas no campo de análise. Para ele, no entanto, essas ideologias não seriam fontes de erro, ou de uma "falsa consciência”, mas fazem parte do próprio contexto social de construção da verdade. Na tese de doutorado, ele se limita a realizar uma investigação sociológica segundo tal ponto de vista, não intentando retirar disso todas as consequências políticas e epistemológicas possíveis. Mills analisa o pragmatismo sociologicamente, ao mesmo tempo retirando da filosofia pragmatista os elementos que servirão de base à construção intelectual de seu método de raciocínio e seu modelo de verificação da verdade. 0 tema de pesquisa da tese de doutorado de
Mills se torna autorreferente, no sentido de que se trata ao mesmo tempo de um objeto de investigação e de seu referencial teórico na construção de toda investigação.

Em termos gerais, esse seria o arcabouço teórico e metodológico do conjunto da sociologia do conhecimento de Wright Mills. No entanto, ao longo dos cinco capítulos da segunda parte, Mills irá desenvolver todas as suas considerações sociológicas sobre o pensamento de Charles Peirce, iniciando no sexto capítulo com uma reconstrução de sua trajetória intelectual - na qual foram focalizados traços biográficos tais como origem familiar, formação escolar, posições ocupacionais, círculos de amizade etc. -, para em seguida debater detalhadamente os aspectos de suas concepções filosóficas que poderiam estar diretamente relacionadas a essa história de vida. No sétimo capítulo, "0 laboratório do estilo de indagação”, Mills discute o modelo de pensamento de Peirce, a partir das críticas deste às concepções cartesianas de dúvida, introduzindo as noções de ação, hábitos e crenças na construção de uma visão relacional, relativa e não absoluta da verdade. No oitavo capítulo, "0 prático em Peirce", o olhar de Wright Mills se volta, mediante a retomada da máxima pragmática, para o debate ontológico do papel das noções de propósito, ação e signifıcado na construção dos acontecimentos cotidianos da vida social. No nono capítulo, "A definição realista da sociedade”, as concepções filosóficas de Peirce opostas ao nominalismo são debatidas em termos de sua adesão ao método científico. Isso condiz com as afirmações anteriores de Mills, segundo as quais o estilo de filosofia construído por Peirce se relaciona com sua atuação prática como cientista de laboratório. No capítulo final 
da segunda parte, "Componentes sociais da perspectiva de Peirce”, Mills apresenta uma síntese geral de toda a discussão sobre o pensamento do fundador do pragmatismo norte-americano, avançando ao mesmo tempo uma explicação sociológica de suas polarizações conceituais em termos de sua posição marginal no universo acadêmico. "Essas polarizações, por sua vez, devem ser entendidas em termos da permanente situação de Peirce como outsider na academia" (MILLS, 1966, p. 211). A tese de doutorado de Wright Mills representa, nesse sentido, um dos exemplos mais rigorosos de pesquisa empírica no campo da sociologia do conhecimento, aliada à autorreflexão teórica e metodológica sobre os rumos das ciências sociais.

\section{Considerações finais}

0 trabalho pioneiro de Wright Mills no campo da sociologia do conhecimento ficou pouco conhecido em seu país de origem e ainda mais no Brasil. 0 próprio Mills contribuiu para tal situação ao se desinteressar pela publicação de seu trabalho. No entanto, sua tese de doutorado possui sugestões importantes para se pensar a sintese teórica na sociologia e as relações entre teoria e prática nas ciências sociais, de uma maneira bastante diversa daquela que se encontra presente na obra volumosa e rigorosa conceitualmente de Talcott Parsons. Mills foi justamente um dos maiores críticos da chamada grande teoria parsoniana. Suas críticas, porém, não foram suficientes para deslocar a hegemonia de Parsons nos Estados Unidos e nos países latino-americanos durante a década de 1950. Uma investigação mais completa da tese de doutorado de Mills e de outros de seus trabalhos de cunho mais teórico poderiam apontar novos rumos para se pensar as questões teóricas e a própria história da sociologia. Apenas a título de exemplo, suas considerações sobre os processos sociais sugerem caracterizações mais concretas das mudanças históricas das estruturas sociais numa espécie de sociologia histórica. Isso ajudaria a pensar em termos mais realistas as possibilidades de sínteses teóricas nas ciências sociais, comparandose ao elevado grau de abstração conceitual e generalização das grandes teorias. Por fim, a leitura de sua tese de doutorado pode simplesmente servir como fonte de sugestões metodológicas para futuras pesquisas no campo da sociologia do conhecimento em relação a outros temos e outras preocupações de cunho político e teórico.

\section{Referências}

ABBAGNANO, N. Dicionário de filosofia. São Paulo: Martins Fontes, 2007.

ARONOWITZ, Stanley. Taking it Big: C. Wright Mills and the making of political intellectuals. New York: Columbia University Press, 2012.

BECKER, H. S. The Chicago School, so-called. Qualitative Sociology, v. 22, n. 1, p. 3-12.

BOGOMOLOV, A. S. A filosofia americana no século XX. Rio de Janeiro: Civilização Brasileira, 1979.

BRASIL JUNIOR, A. S. Passagens para a teoria sociológica: Florestan Fernandes e Gino Germani. São Paulo: Hucitec, 2013.

BREWER, J. D. C. Wright Mills and the Ending of Violence. Basingstoke: Palgrave Macmillan, 2003.

CAPPER, C. "A Little Beyond": The problem of the Transcendentalist Movement in American history. The Journal of American Philosophy, v. 85, n. 2, p. 502-539, set./1998,.

COHN, G. Males privados, sociologia pública: o legado de Wright Mills. Revista Brasileira de Sociologia, v. 1, n. 1, p. 13-34, jan./jul., 2013. 
COSER, L. A. Sociological theory from the Chicago dominance to 1965. Annual Review of Sociology, v. 2, p. 145-160, ago. 1976.

DODSON, G. R. An interpretation of the Philosophical St. Louis Movement. The Journal of Philosophy, Psychology and Scientific Methods, v. 6, n. 13, p. 337-345, jun./1909.

DUNN, R. G. Toward a pragmatist sociology: John Dewey and the legacy of C. Wright Mills. Pennsylvania: Temple University Press, 2018.

FERNANDES, H. R. Mills, o sociólogo-artesão. In: FERNANDES, H. R. (Eds.). Wright Mills: sociologia. São Paulo: Ática, 1985, p. 7-35.

FRAULEY, J. (Eds.). C. Wright Mills and the Sociological Imagination: Prospects for creative inquire. London: Routledge, 2015.

GROSS, N. Pragmatism, phenomenology, and twentieth-century American Sociology. In: CALHOUN, C. (Eds.) Sociology in America: a history. Chicago: The University of Chicago Press, 2007, p. 183-224.

HAYDEN, T. Radical nomad: C. Wright Mills and his times. New York: Routledge, 2016.

HESS, A. Die politische Soziologie C. Wright Mills: ein Beitrag zur politischen Ideengeschichte. Opladen: Leske \&t Budrich, 1995.

HOROWITZ, I. L. (Eds.). Power, Politics and People: The collected essays of C. Wright Mills. New York: Oxford University Press, 1963.

(Org.). Historia y elementos de la sociología del conocimiento. Buenos Aires: Eudeba, 1964.

. The Intellectual Genesis of C. Wright Mills. In: MILLS, C. Wright. Sociology and Pragmatism: The higher learning in America. New York: Oxford University Press, 1966.

C. Wright Mills: An american utopian. New York: The Free Press, 1983.

JOAS, Hans. Interacionismo simbólico. In: GIDDENS, A.; TURNER, J. Teoria social hoje. São Paulo: Ed. Unesp, 1999, p.127-74.
KERR, K. Postmodern cowboy: C. Wright Mills and a new 21st-century sociology. London: Routledge, 2015.

MANNHEIM, K. Ideologia e utopia. 4. ed. Rio de Janeiro: Guanabara, 1986.

MELTZER, B. N. et al. Symbolic Interactionism: Genesis, varieties and criticism. Boston, London and Henley: Routledge \&t Kegan Paul, 1975.

MENAND, L. The Metaphysical Club: A story of ideas in America. New York: Farrar, Straus, and Giroux, 2001.

MILLS, C. W. Language, Logic and Culture. American Sociological Review, v. 4, n. 5, p. 670-680, out./1939.

The new men of power: America's labor leaders. New York: Harcourt, Brace and Co., 1948.

White Colar: the American middle classes. New York: Oxford University Press, 1951.

The power elite. New York: Oxford University Press, 1956.

Consecuencias metodológicas de la sociología del conocimiento. In: HOROWITZ, I. L. (Org.). Historia y elementos de la sociología del conocimiento. Buenos Aires: Eudeba, 1963, p. 143-156.

Poder e política. Rio de Janeiro: Zahar, 1965.

Sociology and pragmatism: The higher learning in America. New York: Oxford University Press, 1966.

Os marxistas. Rio de Janeiro: Zahar, 1968.

A imaginação sociológica. 2. ed. Rio de Janeiro: Zahar, 1969.

MILLS, W. C.; GERTH, H. Caráter e estrutura social. Rio de Janeiro: Civilização Brasileira, 1973.

MONTECINOS, V. C. Wright Mills and Latin America. In: OAKES, G. (Eds.). The Anthem Companion to C. Wright Mills. London/New York: Anthem Press, 2016.

OAKES, G. (Eds.). The Anthem Companion to C. Wright Mills. London/New York: Anthem Press, 2016. 
RODRIGUES, C. T. Guerra, abolicionismo e o nascimento do Pragmatismo (resenha). Cognitio, São Paulo, v. 4, n. 1, p. 134-142, jan.-jun. 2003.

SOUSA, R. F. A nova esquerda americana: de Port Huron aos Weathermen (1960-1969). Rio de Janeiro: FGV, 2009.

STERNE, J. C. Wright Mills, the Bureau for Applied Social Research, and the meaning of critical scholarship. Cultural Studies - Critical Methodologies, v. 5, n. 1, p. 65-94, february/2005.

SUMMERS, J. H. Perpetual revelations: C. Wright Mills and Paul Lazarsfeld. Annals of the American Academy of Political and Social Science, v. 608, p. 25-40, nov./2006.

The epigone's embrace: Irving Louis Horowitz on C. Wright Mills. The Minnesota Review, v. 68, p. 107-124, 2007.

The cultural break: C. Wright Mills and the Polish October. Intellectual History Review, v. 18, n. 2, p. 259-273, jul./2008a.

The epigone's embrace, Part II: C. Wright Mills and the New Left. Left History, Toronto, v. 13, n. 2, p. 94-127, 2008b.

(Eds.) The Politics of Truth: Selected writings of C. Wright Mills. New York: Oxford University Press, 2008c.

TILMAN, R. C. Wright Mills: A native radical and his American intellectual roots. University Park: Pennsylvania State University Press, 1984.

TREVIÑO, A. J. The Social Thought of C. Wright Mills. London: SAGE Publications, 2012.

C. Wright Mills and the Cuban Revolution: An exercise in the art of sociological imagination. Chapel Hill: University of North Carolina Press, 2017. 
RESUMO

0 sociólogo norte-americano C. Wright Mills (1916-1962) é geralmente conhecido pelos seus estudos sobre estratificação social, elites, classes médias, líderes sindicais e a estrutura de poder nos Estados Unidos. A sua produção teórica de caráter sociológico e de fortes afınidades com a reflexão filosófica foi pouco debatida aqui no Brasil. No entanto, o início de sua trajetória acadêmica se caracteriza justamente por um trabalho de cunho epistemológico no campo da sociologia do conhecimento, a tese de doutorado defendida em 1942 sob o título $A$ sociological account of pragmatism: an essay on the sociology of knowledge. 0 propósito do presente artigo será o de debater esse trabalho seminal, apresentando as afinidades entre a perspectiva sociológica de Mills, o pragmatismo norte-americano e o interacionismo simbólico da Escola de Chicago.

\section{PALAVRAS-CHAVE}

Wright Mills; Sociologia do Conhecimento; Pragmatismo; Interacionismo Simbólico.

\section{ABSTRACT}

The North American sociologist C. Wright Mills (1916-1962) is generally known for his studies on social stratification, elites, middle classes, labor leaders and the power structure of the United States. His theoretical production of sociological character, and with strong affınities with the philosophical reflection, was little debated here in Brazil. However, the beginning of his academic trajectory is precisely characterized by an epistemological labor on the field of sociology of knowledge, the doctoral thesis defended in 1942 with the title $A$ sociological account of pragmatism: an essay on the sociology of knowledge. The aim of this article will be to debate this seminal work, presenting the affinities between the Mills' sociological perspective, the North American pragmatism and the symbolic interectionism of Chicago School.

\section{KEY-WORDS}

Wright Mills; Sociology of Knowledge; Pragmatism; Symbolic Interactionism. 